\title{
Effect of cobalt sulfate contents on the ceramic surface coating using spray technique
}

\author{
Hyun Park ${ }^{\dagger}$ and Kyung-Nam Kim \\ Department of Advanced Materials Engineering, Kangwon National University, Samcheok 245-711, Korea
}

(Received November 18, 2014)

(Revised November 26, 2014)

(Accepted December 5, 2014)

\begin{abstract}
This study was carried on the phenomena in reactivity with the clay surface according to the thickness of the cobalt component coating. In the coated specimen, it was observed that the cobalt component was spreaded to diffuse with a constant thickness from the surface of it and the diffusion layer at the white porcelain soil was more increased with the increase of the amount of cobalt sulfate than at the celadon porcelain one. It was evaluated that the color of the surface on the coated specimen at the white porcelain soil was changed from grayish blue to blue and the $\mathrm{L}^{*}$ value was decreased from 51.78 to 37.61 and also in the case of the coated specimen in celadon porcelain soil, $\mathrm{L}^{*}$ value was from 53.91 to 38.93 and the color was from dark olive gray to dark gray. The physical properties of the specimen were characterized by X-ray diffraction, Scanning electron microscope, Dilatometer, TG-DTA, UV-vis spectrophotometer and HRDPM.
\end{abstract}

Key words Ceramic pigment, Cobalt sulfate, Spinel, Olivine

\section{스프레이 기술을 이용한 세라믹 표면 코팅에 대한 황화코발트 첨가량의 영향}

박현", 김경남

강원대학교 신소재공학과, 삼척, 245-711

(2014년 11월 18일 접수)

(2014년 11월 26일 심사완료)

(2014년 12월 5일 게재확정)

요 약 본 연구는 코발트 코팅 두께에 따른 점토 표면과의 반응성을 연구하였다. 시편에서 표면으로 부터 일정한 두께 로 코발트가 확산된 것을 볼 수가 있으며, 황화코발트의 도포양과 함께 청자토보다 백자토에서 확산층의 두께가 증가하였 다. 백자토에 코팅된 시편은 grayish blue가 blue 색으로 변화되는 것을 알 수 있으며 $\mathrm{L}^{*}$ 값이 51.78에서 37.61로 감소하고, 청자토에 코팅된 시편인 경우 dark olive gray에서 dark gray색으로 $\mathrm{L}$ *값이 53.91에서 38.93로 적어지는 것을 알 수가 있다. 시편의 물성 평가는 XRD, SEM, 열팽창기, TG-DTA, UV-vis spectrophotometer와 HRDPM을 이용하였다.

\section{1. 서 론}

세라믹은 점토, 장석, 도석 등의 소지를 혼합하고 성형 하여 초벌 소성한 후 표면에 사용 용도에 따라 유약 등 을 시유하고 2차 소성하여 타일, 도자기 등에 활용하였 다. 그 중 유약의 다양한 발색은 외형적으로 기물의 외 형을 보다 미려하게 치장하는데 그 의미가 있으며 세라 믹 산업의 도자기, 타일 등의 발전과 함께 소지와 유약 은 우리의 일상생활과 함께 진행되어 왔다 $[1,2]$. 세라믹

\footnotetext{
Corresponding author

Tel: +82-33-570-6564

Fax: $+82-33-570-6557$

E-mail: hipark@kangwon.ac.kr
}

스의 우수한 기계적, 화학적 특성을 그대로 유지하면서 다양한 색상을 나타내기 위해서는 그에 알맞은 안료의 개발이 필수적이다. 세라믹스의 안료로는 산화물이 대부 분이고 고온에서 가장 안정한 안료로는 spinel 구조를 형성하는 안료가 많이 이용되고 있다. 그중 코발트를 활 용한 안료는 과거부터[3] 많이 활용되고 있는 물질로 비 교적 안정된 발색을 보이는 $\operatorname{spinel}\left(\mathrm{CoAl}_{2} \mathrm{O}_{4}\right)$ 상과 olivine $\left(\mathrm{Co}_{2} \mathrm{SiO}_{4}\right)$ 상에 대한 많은 연구가 있었다[4-6]. 이들 조성 에 대한 연구는 대부분 $\mathrm{CoAl}_{2} \mathrm{O}_{4}$ 상의 산화물을 합성하여 안료로서 응용하는 연구를 하였으나[7-10], 소성 중에 코 발트가 소지와 반응하여 화합물을 형성하는 연구는 규명 되어 있지 않다. 그리고 소지는 소성과정에서 여러 단계 의 상전이 과정으로 진행되며[11, 12], 도포되는 물질에 
따라 다양한 물질의 화합물을 형성한다. 따라서 이전 연 구에서는 소지의 종류에 따른 코발트의 코팅을 연구하였 으며[13], 소지 층 위의 코팅 두께에 따른 현상들은 소 지의 표면에서 생성되는 상들과 밀접한 관련이 있을 것 으로 생각되며 이에 대한 연구가 필요하다.

본 연구는 소지의 표면층의 두께를 조절하기 위해 황 화코발트 양을 변화시켰으며, 소지의 표면과의 새로운 상에 따른 현상들을 규명하기 위해 스프레이를 이용하여 코팅을 하였다.

\section{2. 실험방법}

시험에 사용된 원료는 백자토(white clay), 청자토 (celadon clay) 소지와 코팅 안료는 황화코발트 $\left(\mathrm{CoSO}_{4}\right.$. $6 \mathrm{H}_{2} \mathrm{O}$ )를 이용하였고, 시편은 판상 작업을 통해 일정한 크 기로 성형하여 자연건조 한 후 시편을 전기로에서 $800^{\circ} \mathrm{C}$ 로 1 차 소성하였다. 소성한 시편은 물에 용해된 안료 $\left(\mathrm{CoSO}_{4} \cdot 6 \mathrm{H}_{2} \mathrm{O}\right)$ 를 스프레이를 이용하여 1 회, 3 회, 5 회 각 각 도포하여 일정시간 건조하였다. 시편의 2 차 소성은 일 반 전기로를 이용하여 $1250^{\circ} \mathrm{C}$ 까지 올린 후 로냉 하였다.

시편의 특성은 X-선 회절분석기(D/Max-2200, Rigaku, Japan)를 이용하여 결정구조를 분석하였으며, 소성온도에 따른 소지 시편의 상 변화는 시차열분석기(STA409PC, Luxx, NETSCH, Germany)와 열팽창계수 측정기(NETSCH, Germany)를 이용하여 특성 변화를 측정하였다. 미세구 조는 고분해능 편광현미경(DM4500P, Leica, Germany) 과 주사전자현미경(JSM-6300, JEOL, Japan)을 각각 이 용하여 관찰하였다. 소성된 시편 표면의 색상분석은 UVvis spectrophotometer (240-pc, Shimadzu, Japan)를 사 용하였으며, Muncell 색 표시인 색상 $(\mathrm{H}: \mathrm{hue})$, 명도(V: value), 채도(C: chroma)와 CIE-L" a ${ }^{*} b^{*}$ 값으로 나타내었다.

\section{3. 결과 및 고찰}

소지의 화학성분은 백자토와 청자토에서 $\mathrm{SiO}_{2}$ 함량이 $72.1 \mathrm{wt} \%, 55.9 \mathrm{wt} \%$ 이고 $\mathrm{Al}_{2} \mathrm{O}_{3}$ 의 경우 $22.6 \mathrm{wt} \%, 32.0 \mathrm{wt} \%$ 이며, $\mathrm{CaO}$ 함량은 청자토에서 $4.3 \mathrm{wt} \%$ 로 많이 포함하고 있으며 모든 소지에서 $\mathrm{K}_{2} \mathrm{O}$ 가 높은 값을 가지고 있다. 결정상은 백자토가 quartz( $\mathrm{SiO})$, muscovite $(\mathrm{KAlSiAlO}(\mathrm{OH}))$, $\mathrm{KAlSiO} \cdot \mathrm{xHO}$, 청자토는 quartz(SiO), anorthite(CaAlSiO), halloysite $(\mathrm{AlSiO}(\mathrm{OH}))$ 로 구성되어 있다[13]. 이들 소지를 $800^{\circ} \mathrm{C}$ 에서 1차 소성한 시료의 결정상은 백자토가 quartz $(\mathrm{SiO}), \mathrm{KAlSiO}_{11}$, 청자토 소지는 quartz( $\left.\mathrm{SiO}\right)$, Albite, $\mathrm{KAlSiO}_{11}$ 상으로 구성되었다.

온도에 따른 소지의 열적성질과 수축률을 위해 TG-
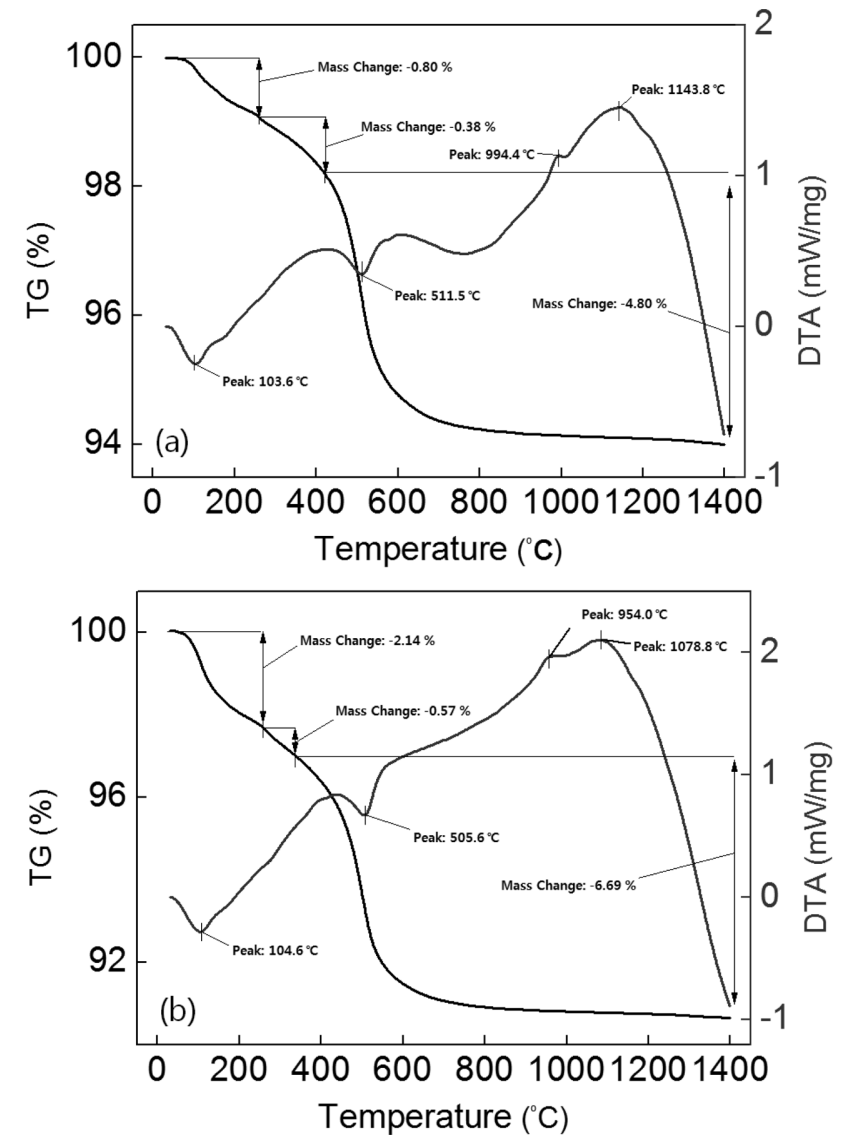

Fig. 1. TG-DTA analysis of (a) white clay and (b) celadon clay for raw material.

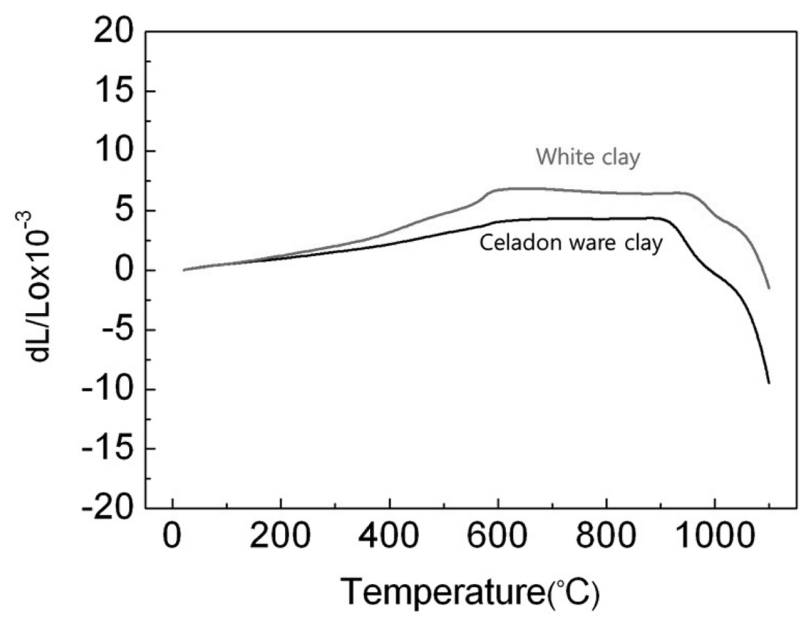

Fig. 2. Linear shrinkage as a function of temperature for the white clay and celadon clay (heating rate, $10^{\circ} \mathrm{C} / \mathrm{min}$ ).

DTA와 dilatometer를 이용하였으며 그 결과를 Fig. 1과 Fig. 2에 각각 나타내었다. 열분석 측정결과 점토의 특성 인 $510^{\circ} \mathrm{C}$ 부근의 흡열피크는 카올린 광물의 $\mathrm{OH}$ 기의 분 리에 의한 것으로 급격한 무게 감량을 동반하고 있으며, $950 \sim 1000^{\circ} \mathrm{C}$ 사이의 발열 피크는 $\mathrm{Al}-\mathrm{Si}$ 스피넬과 알루미 나로의 상 전이가 진행된 것으로 본다[11, 12]. 그리고 
백자토가 청자토 보다 상전이 온도가 높은 것을 볼 수 있으며, 무게 감량은 $700^{\circ} \mathrm{C}$ 이후에는 큰 변화가 없으며 전체 무게감량은 백자토와 청자토가 $6.0 \mathrm{wt} \%, 9.0 \mathrm{wt} \%$ 정도로 각각 나타나고 있다.

소지의 온도증가에 따른 열팽창 수축의 결과 백자토 시 편은 $600^{\circ} \mathrm{C}$ 부근에서 급격한 팽창이 진행되고 $1000^{\circ} \mathrm{C}$ 부 근에서 수축이 진행되는 것을 알 수가 있으며, 청자토는 $950^{\circ} \mathrm{C}$ 부근까지 서서히 팽창하고 그 후 급격하게 수축하 는 것을 알 수 있다. 급격한 팽창은 카올린의 $\mathrm{OH}$ 기 분리 에 나타나는 현상으로 볼 수가 있으며 $[11,12]$, 팽창과 수 축 현상은 소지의 상전이 과정과 함께 진행되는 것을 알 수가 있다. 이는 Fig. 1의 열분석 결과와도 일치한다.

소지를 저온에서 소성한 후 여러 두께의 황하코발트를 코팅하여 소성한 시편 표면의 결정상을 조사하였으며 그 결과를 Fig. 3, 4에 각각 나타내었다. 세라믹소지 표면의 결정상은 모든 소지에서 quartz $\left(\mathrm{SiO}_{2}\right), \operatorname{mullite}\left(3 \mathrm{Al}_{2} \mathrm{O}_{3}\right.$. $2 \mathrm{SiO}_{2}$ )상 및 $\mathrm{CoAl}_{2} \mathrm{O}_{4}$ 상이 나타나고 있다. 백자토 시편

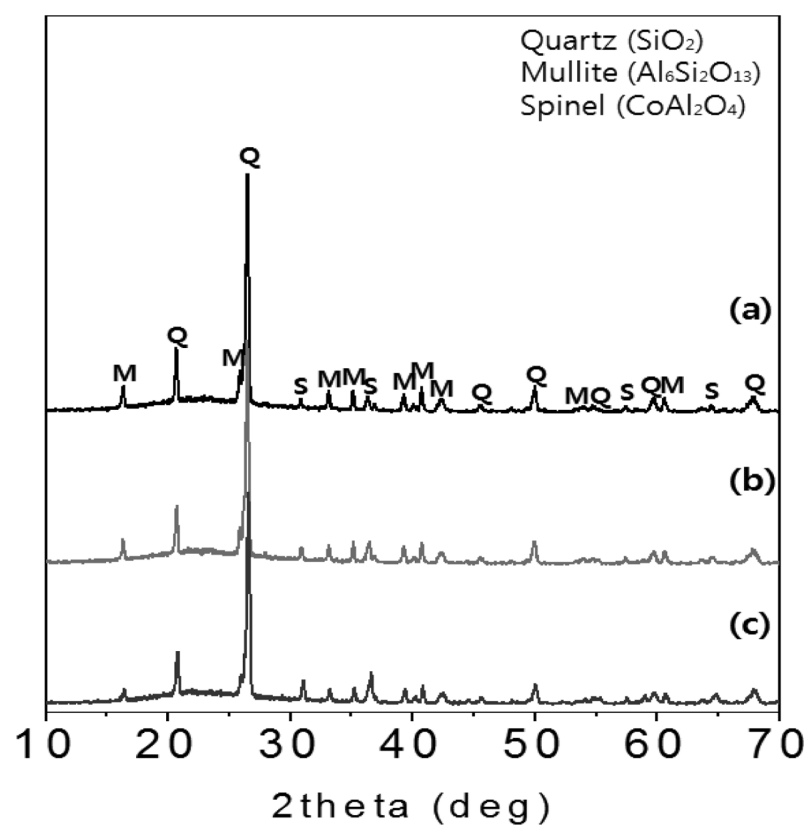

Fig. 3. XRD analysis of white clay specimen coated (a) 1 time, (b) 3 times, and (c) 5 times with cobalt sulfate sintered at $1250^{\circ} \mathrm{C}$.
에서는 코발트 도포 양 증가와 함께 mullite 상 피크의 intensity는 감소하고 $\mathrm{CoAl}_{2} \mathrm{O}_{4}$ 상 intensity는 증가하고 있는 것을 볼 수가 있다. 청자토의 경우는 mullite상과 anorthite 상이 주 피크로 나타나고 $\mathrm{Co}_{2} \mathrm{SiO}_{4}$ 상과 $\mathrm{CoAl}_{2} \mathrm{O}_{4}$ 상이 보 이고 있으며, 코발트의 도포양 증가와 함께 $\mathrm{Co}_{2} \mathrm{SiO}_{4}$ 상의 intensity는 증가하고 $\mathrm{CoAl}_{2} \mathrm{O}_{4}$ 상 intensity는 감소하는 것 을 볼 수가 있다. 이와 같은 결정상은 출발물질의 소지 와 밀접하게 관계하는 것을 알 수 있다. 소지의 표면에 황하코발트 도포 양을 달리하여 높은 온도로 소성하면 소지의 성분이 상전이 과정에서 $\mathrm{Al}-\mathrm{Si}$ 스피넬, 알루미나, 실리카로의 상 전이가 진행된다 $[11,12]$. 그러므로 코발 트와 알루미나, 실리카가 고상반응에 의해 새로운 화합 물인 $\mathrm{CoAl}_{2} \mathrm{O}_{4}$ 상과 $\mathrm{Co}_{2} \mathrm{SiO}_{4}$ 상이 형성되는 것을 알 수가 있다. 그리고 코발트의 도포 두께에 따라 $\mathrm{CoAl}_{2} \mathrm{O}_{4}$ 상에 대한 생성량이 증가하고, 소지에 따라 표면에 생성되는 화합물이 서로 다른 것을 알 수 있다[13, 14].

코발트 코팅 양에 따른 시편의 단면을 절단 연마하여

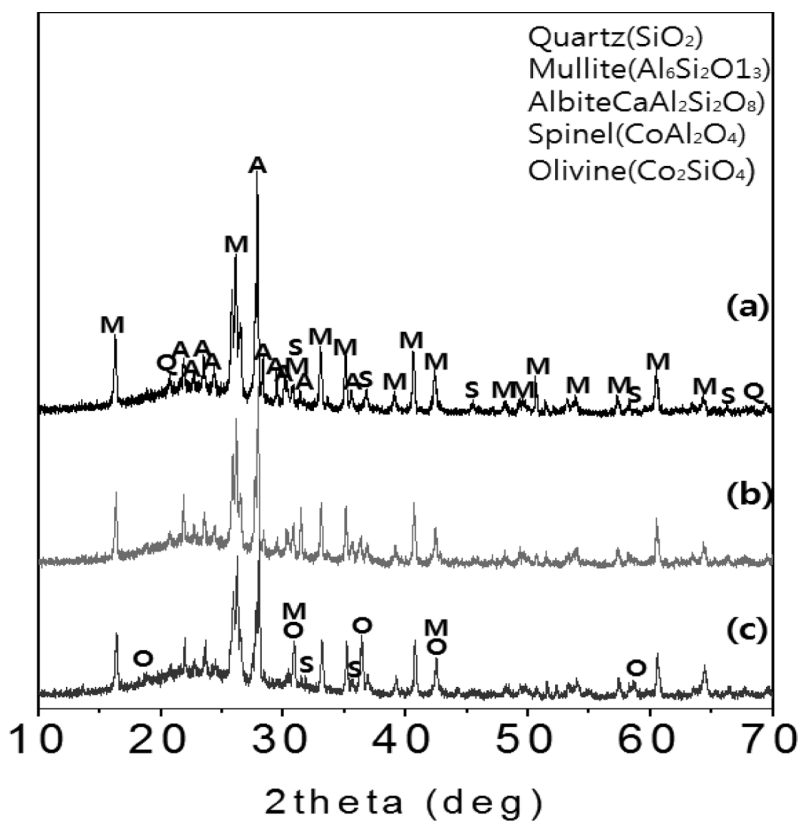

Fig. 4. XRD analysis of celadon clay specimen coated (a) 1 time, (b) 3 times, and (c) 5 times with cobalt sulfate sintered at $1250^{\circ} \mathrm{C}$.
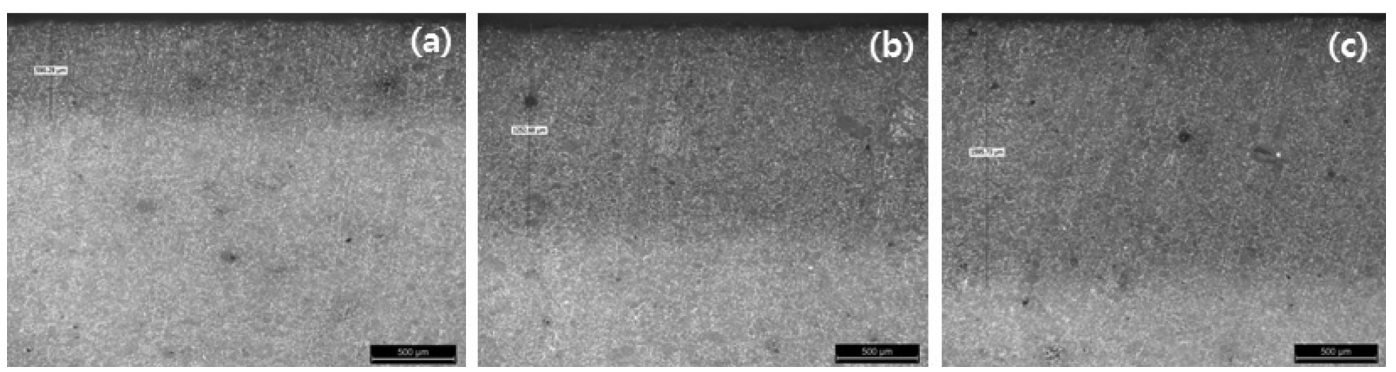

Fig. 5. Optical microscopy of white clay coating with cobalt sulfate contents sintered at $1250^{\circ} \mathrm{C}$ (bar $500 \mu \mathrm{m}$ ). 

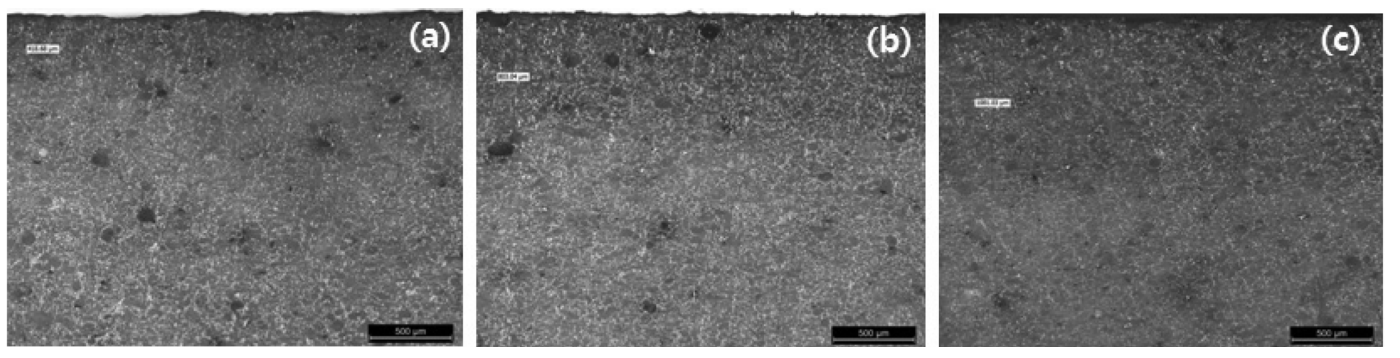

Fig. 6. Optical microscopy of celadon clay coating with cobalt sulfate contents sintered at $1250^{\circ} \mathrm{C}(\mathrm{bar} 500 \mu \mathrm{m})$.
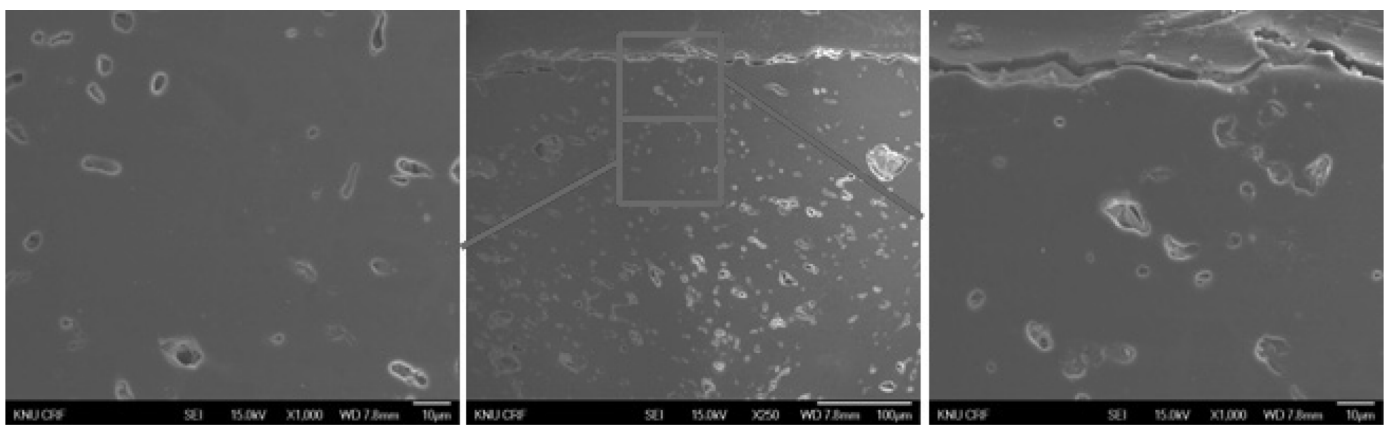

Fig. 7. SEM images of white clay coating with cobalt sulfate sintered at $1250^{\circ} \mathrm{C}$.

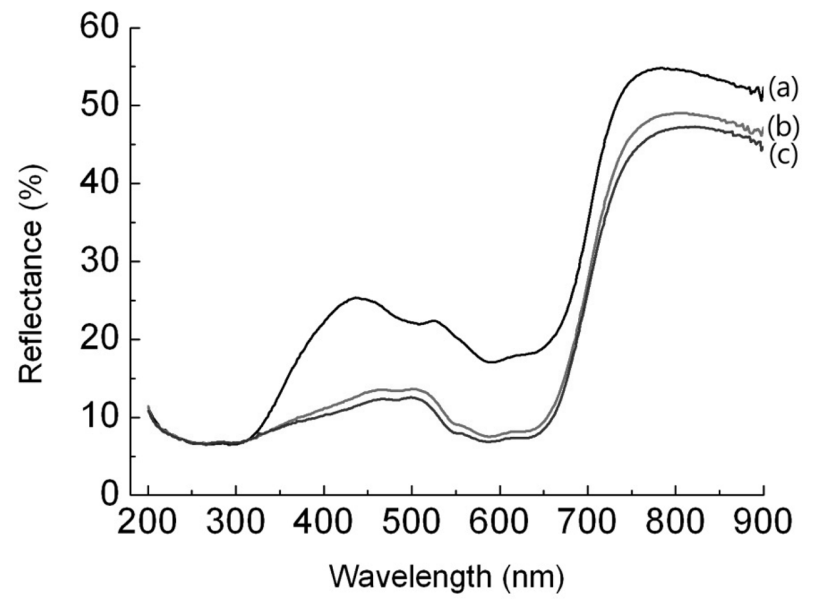

Fig. 8. UV-vis spectra of white clay specimen coated (a) 1 time, (b) 3 times, and (c) 5 times with cobalt sulfate sintered at $1250^{\circ} \mathrm{C}$.

고분해능 편광현미경 관찰한 결과를 Fig. 5와 Fig. 6에 각각 나타내었다. 시편에서 표면으로 부터 일정한 두께 로 코발트가 확산된 것을 볼 수가 있으며, 백자토에 코 팅된 경우 코발트 도포양이 증가와 함께 $590.1 \mu \mathrm{m}$ 에서 $1595.7 \mu \mathrm{m}$ 으로 청자토에 코팅된 경우 $418.7 \mu \mathrm{m}$ 에서 1081 $\mu \mathrm{m}$ 으로 확산이 진행된 것을 볼 수 있다. 코발트 도포 양이 적은 경우 소지의 종류에 따라 큰 차이가 없으나, 도포되는 양이 증가 할수록 백자 소지가 청자 소지 보다 확산두께가 큰 것을 볼 수가 있으며, 이는 Fig. 2에서 보인 시편의 열팽창 과정과 밀접한 관계가 있을 것으로 생각된다. 백자토 시편들의 미세구조 및 기공 형상을 관

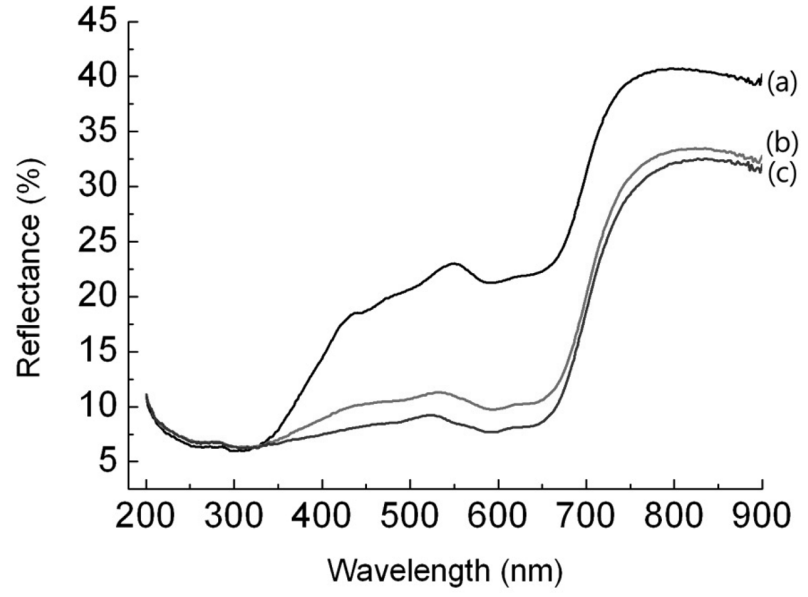

Fig. 9. UV-vis spectra of celadon clay specimen coated (a) 1 time, (b) 3 times, and (c) 5 times with cobalt sulfate sintered at $1250^{\circ} \mathrm{C}$.

찰한 결과를 Fig. 7에 나타내었다. 미세구조는 표면과 내부 모두 치밀한 구조를 보이고 있었다. 시편 모두 다 양한 크기의 기공들이 나타나는 것을 볼 수 있다.

시편 표면 색상은 UV-vis spectrometer로 분석하였으 며 결과를 Fig. 8, 9와 Table 1에 각각 나타내었다. 백자 토에 코팅된 시편에서는 코팅 두께가 증가할수록 grayish blue가 blue 색으로 변화되는 것을 알 수 있으며 $\mathrm{L}^{*}$ 값이 51.78 에서 37.61 로 감소하고, 청자토에 코팅된 시편인 경우 dark olive gray에서 dark gray색으로 $\mathrm{L}^{*}$ 값이 53.91 에서 38.93로 적어지는 것을 알 수가 있다. 이는 백자토 에 코팅된 코발트가 $\mathrm{CoAl}_{2} \mathrm{O}_{4}$ 상을 형성 하면서 blue색을 
Table 1

Optical property of cobalt sulfate coating ceramic

\begin{tabular}{lllllll}
\hline Sample & $\mathrm{L}^{*}$ & $\mathrm{a}^{*}$ & $\mathrm{~b}^{*}$ & $(\mathrm{H})$ & $(\mathrm{v}) /(\mathrm{c})$ & Color name \\
\hline Celadon C1 & 53.91 & -2.61 & 5.61 & $2.31 \mathrm{GY}$ & $5.23 / 0.83$ & Light olive gray \\
Celadon C3 & 38.93 & -2.40 & 1.12 & $2.93 \mathrm{G}$ & $3.78 / 0.48$ & Dark gray \\
White C1 & 51.78 & -1.71 & -8.02 & $1.94 \mathrm{~PB}$ & $5.02 / 2.10$ & Grayish blue \\
White C3 & 37.61 & -3.93 & -9.02 & $8.89 \mathrm{~B}$ & $3.65 / 2.25$ & Blue \\
\hline
\end{tabular}

나타내고 있으며 $[4,6,14]$, 그리고 청자토의 경우는 $\mathrm{CoAl}_{2} \mathrm{O}_{4}$ 상과 $\mathrm{Co}_{2} \mathrm{SiO}_{4}$ 상 형성 보다는 새로운 결정상이 지배하여 gray 색을 보이는 것으로 생각된다. 이는 표면 에 코팅된 두께에 따라 화합물 형성되는 양이 달라지며 이는 표면의 색상 변화에도 많은 영향을 미치는 것으로 생각된다.

\section{4. 결 론}

세라믹소지에 코발트의 코팅 두께에 따른 반응성과 표 면에서 나타나는 현상들을 실험한 결과는 다음과 같다.

시편에서 표면으로 부터 일정한 두께로 코발트가 확산 된 것을 볼 수가 있으며, 황화코발트의 도포 양과 함께 청자토 보다 백자토에서 확산층이 많이 진행되었고, 백자 소지는 $\mathrm{CoAl}_{2} \mathrm{O}_{4}$ 상이 증가 하였으며, 청자소지는 $\mathrm{Co}_{2} \mathrm{SiO}_{4}$ 상과 $\mathrm{CoAl}_{2} \mathrm{O}_{4}$ 상이 함께 나타나고 $\mathrm{Co}_{2} \mathrm{SiO}_{4}$ 상이 증가하 는 것을 볼 수가 있다.

백자토에 코팅된 시편에서는 grayish blue가 blue 색으 로 변화되는 것을 알 수 있으며 $\mathrm{L} *$ 값이 51.78에서 37.61 로 감소하고, 청자토에 코팅된 시편인 경우 dark olive gray에서 dark gray색으로 $\mathrm{L}$ *값이 53.91에서 38.93로 적어지는 것을 알 수가 있다. 이는 백자토에 코팅된 코 발트가 $\mathrm{CoAl}_{2} \mathrm{O}_{4}$ 상을 형성 하면서 blue색을 나타내고 있 으며, 그리고 청자토의 경우는 $\mathrm{CoAl}_{2} \mathrm{O}_{4}$ 상과 $\mathrm{Co}_{2} \mathrm{SiO}_{4}$ 상 형성 보다는 새로운 결정상이 지배하여 gray 색을 보이 는 것으로 생각된다.

\section{감사의글}

본 연구는 2014년도 강원대학교 학술연구조성비로 연 구하였음(관리번호-220140064).

\section{References}

[1] A. Burgyan and R.A. Eppler, "Classification of mixedmetal-oxide inorganic pigment", Am. Ceram. Bull. 62
(1983) 1001.

[2] R.A. Eppler and D.R. Eppler, Glazes and Glass Coatings, The American Ceramic Society, Westerville, Ohio, USA (2000).

[3 ] M.O. Figueiredo, T.P. Silva and J.P. Veiga, "A XANES study of cobalt speciation state in blue-and-white glazes from 16th to 17th century Chinese porcelain", J. Elec. Spec. \& Rela. Pheno. 185 (2012) 98.

[4] G. Monari and T. Manfredini, "Coloring effects of synthetic inorganic cobalt pigments in fast-fired porcelainized tiles", Ceram. Eng. Sci. Proc. 17 (1996) 167.

[5] S. Djambazov, Y. Ivanova, A. Yoleva and N. Nedelchev, "Ceramic pigments on the base of the CoO$\mathrm{ZnO}-\mathrm{SiO}_{2}$ system obtained by a sol-gel method", Ceram. Int. 24 (1998) 281.

[6] M. Llusar, A. Fores, J.A. Badenes, J. Calbo, M.A Tena and G. Monros, "Colour analysis of some cobalt-based blue pigments", J. Euro. Ceram. Soc. 21 (2001) 1121.

[7] W. Li, J. Li and J. Guo, "Synthesis and characterization of nanocrystalline $\mathrm{CoAl}_{2} \mathrm{O}_{4}$ spinel powder by low temperature combustion", J. Euro. Ceram. Soc. 23 (2003) 2289.

[ 8 ] Z.Z. Chen, E.W. Shi, W.J. Li, Y.Q. Zheng, J.Y. Zhuang, B. Xiao and L.A. Tang, "Preparation of nanosized cobalt aluminate powders by a hydrothermal method", Mat. Sci. \& Eng. B 107 (2004) 217.

[9] D.Y. Shin, K.N. Kim and S.M. Han, "Synthesis and characterization of nano-size $\mathrm{CoAl}_{2} \mathrm{O}_{4}$ spinel powder using sol-gel process", Mat. Sci. Forum 544-545 (2007) 869.

[10] K.C Lee, J.W. Yoon, J.H. Kim, K.T. Hwang and K.S. Han, "Preparation and characterization of $\mathrm{CoAl}_{2} \mathrm{O}_{4}$ blue ceramic nano pigments by attrition milling", J. Korean Cryst. Growth Cryst. Technol. 23 (2013) 255.

[11] W.M. Carty and U. Senapati, "Porcelain-raw materials, processing, phase evolution, and mechanical behavior", J. Am. Ceram. Soc. 81 (1998) 3.

[12] O. Castelein, B. Soulestin, J.P. Bonnet and P. Blanchart, "The influence of heating rate on the thermal behaviour and mullite formation from a kaolin raw material", Ceram. Int. 27 (2001) 517.

[13] I.A. Won and K.N. Kim, "Reactions of various ceramic materials with cobalt sulfate solution", Kor. J. Mater. Res. 24 (2014) 93.

[14] C. Jing and S.X. Hanbing,"The preparation and characteristics of cobalt blue colored mica titania pearlescent pigment by microemulsions", Dyes and Pigments 75 (2007) 766. 